\title{
LET'S TALK! PROMOTING MEANINGFUL COMMUNICATION THROUGH AUTHENTIC TEACHER CHILD DIALOGUE
}

\author{
Barbara Shapir, Teresa Lewin (Dr.), \& Samar Aldinah \\ Kaye College of Education- Early Educational Department (Israel)
}

\begin{abstract}
The heart of this study is an analysis of teacher-child dialogue in a classroom environment. An authentic dialogue enables children to express their real thoughts and ideas, to present insights, to ask questions, to make comments and to argue about different interpretations.

In an effort to help our future teachers improve the quality of their verbal and nonverbal interactions with children as well as emotional and social support, we created a "community of learners". Mentors and eight students - teachers (Israeli Jews and Arabs) participated in a reciprocal process of learning through experimentation while building new knowledge. Their interactions were examined how the teachers' verbal and nonverbal responsiveness helped them to open or close conversational spaces for children while enabling them to listen to their voices.

The research methodology was a discourse analysis i.e. analyzing the use of language while carrying out an act of communication in a given context. It presents a qualitative analysis of 20 transcripts of students teacher's conversations with Israeli Jewish and Arab children from ages $4-6$ years old. The analysis revealed that as teachers provided open conversational spaces with children, authentic dialogue emerged. Both voices were expressed and the child's world was heard. The significance of this study is to demonstrate the importance that authentic dialogue between teachers and young children has on the learning process as well as teacher's acknowledgment on how children think and feel. This offers an opportunity for them to learn with and from the children.
\end{abstract}

Keywords: Authentic dialogue, verbal \& nonverbal interactions.

\section{Introduction}

This study has grown out of a learning community that has been operating for the past three years in the Early Childhood Educational Department at the Kaye Academic College of Education (Beer Sheva, Israel). The main goal was to study and promote teacher-children quality interactions, focusing on optimal discourse that provides emotional and social support. The learning community consisted of Jewish and Arab lecturers teaching training classes.

\section{The role of dialogue in education}

Dialogue is essential in human relationships in order to reach understandings and consensus among people. Meaningful dialogue in classroom interactions is of pivotal importance because it affects both teachers' and students' sense of security and wellbeing, as well as the quality of students' learning processes and achievements. (Hennessy et al., 2016; Teachman et al., 2018; Vrikki et al., 2019).

Despite the recognition of the importance of reciprocal dialogue, the prevailing form of teacher-student interactions continue to be the traditional structure IRE (Initiation-Reply-Evaluation) (Mehan and Cazden, 2015) or IRF (Initiation-Response-Feedback) (Sinclair \& Coulthard, 1975). This holds true in kindergartens as well. Classrooms and early childhood settings which have followed this pattern have excluded many minority students, as it does not encourage them to actively participate in the classroom talk.

In early childhood education, discourse is especially important and is regarded as the main pedagogical tool of kindergarten teachers. The social learning climate that the teacher provides will determine the quality of their interactions with children and success in school. (McNally \& Slutsky, 2018; Myers \& Sheddield, 2009). In the teacher's role perception of classroom discourse she sees herself in a 
parental role, and by virtue of this role, has the authority and responsibility to be in control, navigate and lead the classroom interaction (Peled-Elhanan \& Blum-Kulka, 2006).

In order to promote personal discourse, the early childhood teacher should foster a supportive environment, sensitively addressing children's interests, characteristics and needs. This requires providing open discourse spaces that will allow children to make their voices heard and express their thoughts and experiences. This discourse has been termed authentic dialogue (Nystrand et al., 2003)

Authentic dialogues can occur only if the different perspectives given by the children are accepted and not judgementally rejected. When a teacher withholds the urge to control the child's thinking or reprimand their behaviour, she can actively listen and be attentive to the children's needs. Respectful and responsive interactions that also honor cultural beliefs and values will strengthen the teacher's relationships with the children and their families (Barrera, Corso \& MacPherson, 2003; Strickland \& Marinak, 2015). Nystrand and his colleagues defined this space as a "positive interaction area" in which many children participate, build on each other's ideas and ask questions enthusiastically and out of interest (Nystrand et al., 2003).

\section{Problem statement}

Previous research has proven the significance of insightful and authentic dialogue in educational settings. However, early childhood teachers often do not fully recognize this and additionally, are not sufficiently trained in conducting authentic, meaningful dialogues with children. Furthermore, educators and researchers often fail to understand the power relationships and values that dialogues convey, as well as the need of addressing cultural norms and multiple perspectives (Guilherme \& Morgan, 2020). We adhere to the view that personal and meaningful dialogues are those which open spaces for diverse perspectives, for the understanding and the construction of new meanings and the development of children's' critical and independent thinking.

\section{Purpose of the study}

To describe, and characterize the dialogue between preservice teachers and children.

\section{Research questions}

What characterizes the dialogue between preservice teacher's and children? Specifically, to what extent did the preservice teacher's implement principles of authentic dialogue they learned?

\section{Research methods}

The research methodology was a discourse analysis i.e., analyzing the use of language while carrying out an act of communication in a given context (Schiffrin, Tannen \& Hamilton, 2001). The work is grounded in the sociolinguistic approach, emphasizing the functionality of language (Vardi-Rath, Teubal, Aillenberg \& Lewin, 2014).

\subsection{Participants}

Participants are 8 Israeli students - teachers (4 Jewish and 4 Arab) in their third and final training year. All of them took part in a community of learners that consisted of pedagogical advisors and lecturers from the early childhood department in the college in a reciprocal process of learning through experimentation while building new knowledge. Sixteen kindergarten children, ages 3-6 years old (8 Jewish and $8 \mathrm{Arab}$ ) participated in the research as well as the dialogue was conducted with them.

\subsection{Research tools and data processing}

Each preservice teacher conducted three personal conversations with the same child. The teachers were instructed to start each conversation with an open-ended question (for example: What would you like to tell me? How do you feel? Tell me about yourself), inviting the child to share experiences through story telling. The work presents a qualitative analysis of 20 transcripts of preservice teacher's conversations with children. The study is based on ethnographic data gathering, i.e., recording teacher - children's discourse. During the conversation with a child, preservice teachers videotaped and took notes. After the session, they produced a transcript combining the information from the oral videotapes and written notes. Video is a tool that is used to document authentic situations and additionally, to help teachers learn to critically reflect on their classroom interactions (Borko, Jacobs, Eiteljorg, \& Pittman, 2008). 
The videos were analysed, using a coding scheme that was developed by the researchers and preservice teachers in the community of learners. It is based on a tool designed by Birenbaum at al. (2004), and adapted to the needs of the study. The coding scheme categorizes qualitative analysis teachers' discourse characteristics and the ways they navigated the conversations with the children based on theoretical literature on the subject.

\section{Findings}

The analysis revealed that as teachers provided open conversational spaces with children, authentic dialogue emerged. Both voices were expressed in a more equalitative fashion and the child's world was heard (Strickland \& Marinak, 2015).

Examples of principles used to analyse functions of talk in order to identify patterns in the interaction are: 1. Opening dialogue; opening statement enables the child to pick a topic of his own free will 2. Reciprocal talk: the teacher commented and expressed respect and appreciation for the children's opinions 3. Supportive reactions: participants feel able to express ideas freely, listen to each other, share ideas and consider alternative viewpoints; 4. Type of questions: the teacher provided open questions that were in line with the children's focus of attention and interest; 5 . Sensitive response: the teachers provide space for children's initiatives and enable them to share their experiences while being sensitive and responsive.

\section{Conclusion}

Referring to the question what characterizes the dialogue between preservice teacher's and children, it can be said that in order to promote personal authentic dialogue, the teacher should foster a supportive environment, sensitively addressing children's interests, characteristics and needs. This requires providing open discourse spaces that will allow children to make their voices heard and express their thoughts and experiences. It is important to create open spaces in all areas of preschool environment and activity corners.

What did the staff learn from this process created through a community of learners? Preservice teachers can experience significant learning through hands on experiences while interacting with children after receiving training on the characteristics of authentic dialogue. In addition, through a reflective process, they become more aware of their role in enabling a more equal dialogue. Therefore, it's essential that the preservice teacher's pedagogical advisors guide them and promote reflective thinking.

This research is still ongoing due to the fact that an extensive amount of data has been collected and not yet analyzed. Our analysis did show some conclusions such as both Jewish and Arab children mainly talk about topics close to their world such as family, friends, personal experiences and these issues are related to the social context in which they live.

The significance of this study is to demonstrate the importance that authentic dialogue between teachers and young children has on the learning process as well as teacher's acknowledgment on how children think and feel. This offers them an opportunity to learn from children, together with children.

\section{References}

Barrera, I., Corso, R. M., \& MacPherson, D. (2003). Skilled dialogue: Strategies for responding to cultural diversity in early childhood. Baltimore: Paul H. Brooks Publishing Co.

Birenbaum, M., Yoad, C., Katz, S., \& Qimron, H. (2004), In Continuous Construction - An Environment for the Professional Development of Teachers on the Subject of the Culture of HL, which cultivates self-direction in learning. Jerusalem: Ministry of Education, Culture and Sports. (In Hebrew).

Borko, H., Jacobs, J., Eiteljorg, E., \& Pittman, M. E. (2008). Video as a tool for fostering productive discussions in mathematics professional development. Teaching and Teacher Education, 24(2), 417- 436.

Borko, Hilda \& Jacobs, Jennifer \& Eiteljorg, Eric \& Pittman, Mary. (2008). Video as a tool for fostering productive discourse in mathematics professional development. Teaching and Teacher Education. 24. 417-436.

Guilherme, A., \& Morgan, W.J. (2020) Filosofia, diálogo e educação: nove filósofos europeus modernos. Brasília: Cátedra Unesco de Juventude, Educação e Sociedade, Universidade Católica de Brasília, ISBN:978-85-62258-44-2. (In English). 
Hennessy, S., Rojas-Drummond, S., Higham, R., Marquez, A. M., Maine, F., Ríos, R. M., et al. (2016). Developing a coding scheme for analyzing classroom dialogue across educational contexts. Learning, Culture and Social Interaction, 9, 16-44.

McNally, S., \& Slutsky, R. (2018). Teacher-child relationships make all the difference: constructing quality interactions in early childhood settings. Early Child Development and Care, 188 (5), 508-523.

Mehan, H., \& Cazden, C. (2015). The study of classroom discourse: Early history and current developments. In L.B. Resnick, C. Asterhan, \& S.N. Clarke (Eds.), Socializing intelligence Chapter 4 (pp. 13-36). Washington, DC: American Educational Research Association.

Myers, S.S., \& Sheffield, M., A. (2009). Examining associations between effortful control and teacher-child relationships in relation to Head Start children's socioemotional adjustment. Early Education and Development, 20(5), 756-774.

Nystrand, M., Wu, L., Gamoran, A. Zeiser, S., \& Long, D. (2003). Questions in time: investigating the structure and dynamics of unfolding classroom discourse. Discourse Processes, 35(2), 135-198.

Peled-Elhanan, N., \& Blum-Kulka, S. (2006). Dialogue in the Israeli classroom: Types of teacher-student talk. Language and Education, 20(2), 110-127.

Schiffrin, D., Tannen, D., \& Hamilton, H. E. (Eds.). (2001). The handbook of discourse analysis. Padstow, Cornwall, UK: Blackwell.

Sinclair, J. M., \& Coulthard, M. (1975). Towards an Analysis of Discourse: The English Used by Teachers and Pupils. Oxford: Oxford University Press.

Strickland, M., \& Marinak, B. (2015). Not Just Talk, But a "Dance"! How Kindergarten Teachers Opened and Closed Spaces for Teacher-Child Authentic Dialogue. Early Childhood Education Journal, 43(6), 1-9.

Teachman, G., McDonough, P., Macarthur, C., \& Gibson, B. E. (2018). A critical dialogical methodology for conducting research with disabled youth who use augmentative and alternative communication. Qualitative Inquiry, 24, 35-44.

Vardi-Rath, E., Teubal, E., Aillenberg, H. \& Lewin, T. (2014). “Let's pretend you're the wolf!": The literate character of pretend-play discourse in the wake of a story. In A. Cekaite, S. Blum-Kulka, V. Grover, \& E. Teubal (Eds.), Children's peer talk: Learning from each other (pp. 63-87). Cambridge: Cambridge University Press.

Vrikki, M., Wheatley, L., Howe, C., Hennessy, S., \& Mercer, N. (2019). Dialogic practices in primary school classrooms. Language education, 33, 85-100. 